\title{
Dietary patterns and risk of cervical cancer: a case-control study in Uruguay
}

\author{
Eduardo De Stefani ${ }^{1}$, Gisele Acosta ${ }^{1}$, Hugo Deneo-Pellegrini ${ }^{1}$, Alvaro L. Ronco ${ }^{2}$, María Mendilaharsu ${ }^{1}$, \\ Gabriel Landó $^{1}$, María E. Luaces ${ }^{1}$, Cecilia Silva ${ }^{1}$
}

${ }^{1}$ Epidemiology Group, Department of Pathology, School of Medicine, Montevideo, Uruguay;

${ }^{2}$ Department of Epidemiology and Statistics, University of Maldonado, Maldonado, Uruguay.

Email: edestefani@gmail.com

Received 5 May 2011; revised 30 May 2011; accepted 10 June 2011.

\begin{abstract}
In the time period 1996-2004, a case-control study on diet and cervical cancer was conducted at the $\mathrm{Na}$ tional Cancer Institute in Uruguay. The study included 268 cases and 536 controls with non-neoplastic diseases. The foods and beverages in the foodfrequency questionnaire were included in a factor analytic model. This method retained three factors which were labeled as the drinker, red meat, and prudent patterns. The model explained $60 \%$ of the variance. Whereas the red meat and drinker patterns were directly associated with the risk of cervical cancer (OR for red meat pattern 1.79, 95\% CI 1.12-2.86), on the other hand, the prudent pattern was inversely associated with cervical cancer (OR $0.60,95 \%$ CI 0.38-0.93). To our knowledge, this study was the first one using factor analysis in order to elucidate the role of the diet in relation with cervical cancer.
\end{abstract}

Keywords: Dietary Patterns; Cervical Cancer

\section{INTRODUCTION}

Cervical cancer is the third cancer site in frequency in Uruguay, following breast cancer and colorectal cancer. This malignancy shows an age-standardized incidence rate of 17.5 per 100,000 Uruguayan women [1]. A previous study conducted in Uruguay showed that cancer of the uterine cervix presented a steady decline in mortality from the early fifties until the late eighties [2]. More precisely, in the time period 1953-1957, this decline reached mortality rates of 4.4 per 100,000 women, which implies a relative risk of 0.56 .

The main risk factors for cervical cancer are related to the infection caused by human papilloma virus (HPV) and related sexual activities. Smoking and other environmental risks have been studied in detail $[3,4]$ and tobacco smoke has been considered a potential carcinogen in cervical cancer.

The role of the diet has been examined in a rather small number of studies and the consistency of the findings is limited [3,5]. In a monograph by the World Cancer Research Fund [5] carrots have been suggested as a possible protective vegetable, but aside from this finding, little else is known about the role that diet plays in cervical cancer.

Since traditional approaches to research into cervical cancer have been considered limited due to the high collinearity of individual foods or nutrients, we decided to use factor analysis in this study, in the view that it could offer a new approach in the etiology of cervical carcinoma. This analytical method consists of reducing a large number of foods to a smaller number of factors [6], and has been employed to date in the study of numerous cancer sites [6-10]. We considered that this approach could offer new information regarding the role of diet in the etiology of cervical carcinoma.

\section{SUBJECTS AND METHODS}

\subsection{Selection of Cases}

In the time period 1990-2000 all newly diagnosed and microscopically confirmed patients with carcinoma of the cervix were considered eligible for the study. A total of 274 patients were approached and only 5 refused the interview, leaving a final total of 268 patients (response rate $97.8 \%$ ). Two hundred and sixty (260) patients presented squamous cell carcinoma of the cervix (97.3\%) and 8 patients showed undifferentiated carcinoma $(2.7 \%)$. All the cases were diagnosed by biopsy and were admitted to the National Institute of Cancer, Uruguay.

\subsection{Selection of Controls}

In the same time period and in the same Institute, all female patients with non neoplastic diseases which were 
not related to tobacco smoking or alcohol drinking and without recent changes in their diets were considered eligible for the study. A total of 2,136 patients were asked for voluntary participation in the study, and 2074 accepted the interview. Only 62 women refused the interview (response rate $97.1 \%$ ).

From this pool of controls, 536 patients were included in the study. These controls were randomly selected following a control/case ratio of $2: 1$ and were frequency matched to cases on age and residence. These patients presented the following conditions: sebaceous cyst (140, $26.1 \%)$, seborrheic keratosis $(130,24.2 \%)$, breast abscess $(109,20.3 \%)$, osteomielitis $(55,10.3 \%)$, lipoma $(41,7.6 \%)$, injuries $(26,4.9 \%)$, varicose veins $(16$, $3.0 \%)$, diseases of the genital tract $(11,2.1 \%)$, and hydatid cyst $(8,1.5 \%)$. All the cases and controls were of Hispanic White ancestry.

\subsection{Inteviews and Questionnaire}

All the participants (cases and controls) were interviewed after admission to the Institute by two trained social workers. Proxy interviews were not accepted. The patients were administered a structured questionnaire which included the following sections: sociodemographics (age, residence, education, income), a complete occupational history based on the last four jobs, self reported height and weight 5 years prior to the interview, a complete history of cancer among first-degree relatives, a complete history of smoking (age at start, age at quit, number of cigarettes smoked per day, type of tobacco, type of cigarette), a complete history of alcohol drinking (age at start, age at quit, number of glasses per day or week, type of alcoholic beverage), a complete history of mate consumption (age at start, age at quit, number of litres of the beverage, mate temperature), menstrual and reproductive events (age at menarche, age at menopause, number of livebirths, abortion, age at first pregnancy, age at last pregnancy, breastfeeding, age at first intercourse, number of sexual partners), and a food-frequency questionnaire (FFQ) focused on meat consumption, dairy foods, total vegetables and total fruits.

\subsection{Statistical Analysis}

The food groups were categorized using a Likert-type scale and were introduced in a factor analysis among controls. The factor analysis retained three factors $[6,11]$ after running the scree plot. The factorability was measured through Cronbach alpha and sampling adequacy was tested through the Kaiser-Meyer-Olkin statistic. The factors were then rotated using the orthogonal varimax method and normalized by the Kaiser procedure. The factors were scored through the Thompson regression method [12] and the scores were applied to cases and controls. The scored patterns were correlated by selected variables using Spearman rank correlations.

The relative risks of cervical carcinoma was approximated by the odds ratios, using unconditional multiple logistic regression [13]. In short, we fitted a model which included as independent variables the following terms: age (continuous), residence (categorical), urban/rural status (categorical), education (categorical), smoking index (categorical), number of partners (categorical), age at first intercourse (categorical), total energy intake (continuous), and all three scored dietary patterns. The reason for including all four score patterns is the fact that dietary patterns are conditional on one another. All the calculations were performed using STATA [14].

\section{RESULTS}

The distribution of cases and controls by sociodemographics and tobacco variables is shown in Table 1. As expected from the matched design, age and residence were similar among cases and controls. Also, education and income were similar for both groups of participants. On the contrary, current smokers showed an odds ratio of 1.7 (95\% CI 1.1-2.7) when compared with never smokers. Also, an early age at first intercourse and a high number of sexual partners were directly associated with risk of cervical cancer (OR for high number of partners $2.7,95 \%$ CI 1.6-4.4).

The factor loadings matrix for controls is shown in Table 2. Factor 1 presented high loadings for salted meat, beer, and hard liquor and was labeled as the drinker pattern. The pattern showed a high negative loading for wine consumption and the pattern explained $31.8 \%$ of the variance. Factor 2 displayed high loadings for red meat, and barbecued meat and high negative loading for whole milk and was labeled as the red meat pattern. This pattern explained $16.2 \%$ of the variance. Factor 3 showed high loadings for total vegetables and total fruits and was called the prudent pattern, explaining $12.0 \%$ of the variance. The total variance was $60 \%$, a high value indeed.

Spearman rank correlations between dietary patterns and the selected variables are shown in Table 3. The drinker pattern was inversely associated with age and directly associated with smoking intensity, years smoked, and number of sexual partners. The red meat pattern was inversely associated with age, and directly associated with parity, and early age at first intercourse. Finally, the prudent pattern was highly correlated with education.

Patient characteristics among factor quartiles for controls are shown in Table 4. The drinker pattern displayed a positive gradient for smoking intensity and number of sexual partners and an inverse gradient for red meat in- 
take. The red meat pattern was negatively associated with years of education and a clear increased gradient for means of meat intake. Finally, the prudent pattern displayed a positive gradient for education, raw vegetables consumption and an inverse association with red meat intake.

Table 1. Distribution of cases and controls for sociodemographics, tobacco use, and sexual events.

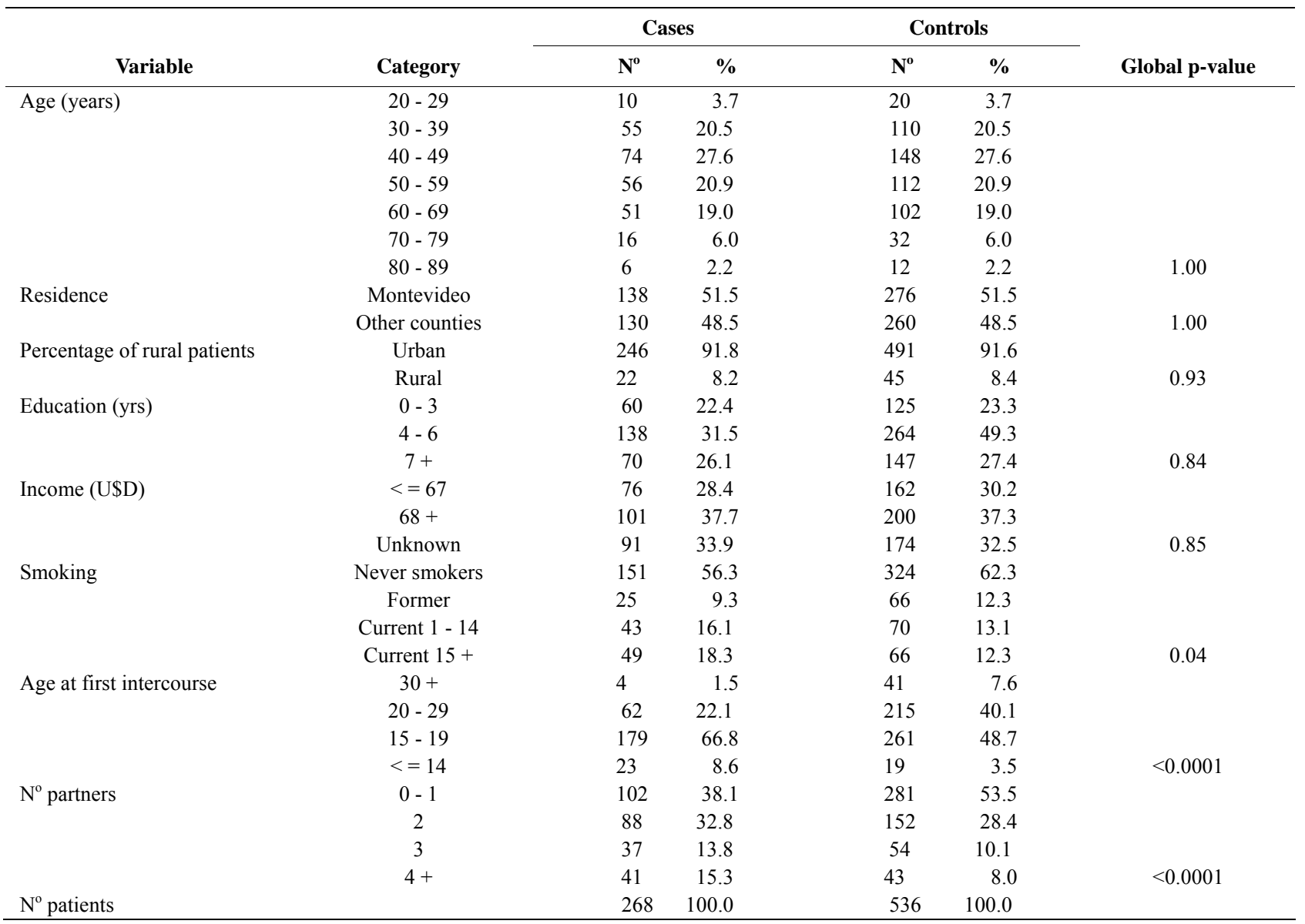

Table 2. Factor loadings matrix among controls ${ }^{1}$.

\begin{tabular}{|c|c|c|c|}
\hline \multirow{2}{*}{ Food groups } & Drinker & Red meat & Prudent \\
\hline & Factor 1 & Factor 2 & Factor 3 \\
\hline Red meat & 0.02 & 0.52 & -0.36 \\
\hline Salted meat & 0.50 & 0.03 & -0.02 \\
\hline Barbecued meat & -0.00 & 0.41 & -0.03 \\
\hline Processed meat & -0.03 & 0.31 & 0.11 \\
\hline Total vegetables & -0.02 & 0.04 & 0.61 \\
\hline Total fruits & 0.04 & -0.08 & 0.56 \\
\hline Beer & 0.51 & 0.02 & 0.02 \\
\hline Wine & -0.46 & 0.08 & -0.00 \\
\hline Hard liquor & 0.52 & 0.01 & 0.00 \\
\hline Mate & -0.02 & 0.34 & -0.11 \\
\hline Cumulative variance & 31.8 & 48.0 & 60.0 \\
\hline
\end{tabular}

${ }^{1}$ Loadings higher than 0.39 are typed in bold. 
Table 3. Spearman rank correlations between dietary patterns and selected variables.

\begin{tabular}{cccc}
\hline \multirow{2}{*}{ Variables } & \multicolumn{3}{c}{ Dietary patterns } \\
\cline { 2 - 4 } & Drinker & Red meat & Prudent \\
\hline Age & $-\mathbf{0 . 1 3}$ & $-\mathbf{0 . 1 9}$ & 0.03 \\
Education & 0.09 & -0.05 & $\mathbf{0 . 2 2}$ \\
Smoking intensity & $\mathbf{0 . 2 1}$ & 0.09 & -0.00 \\
Smoking duration & $\mathbf{0 . 2 0}$ & 0.08 & 0.00 \\
$\mathrm{~N}^{\text {o }}$ of livebirths & 0.02 & $\mathbf{0 . 1 8}$ & -0.07 \\
Age of intercourse & 0.04 & $\mathbf{0 . 1 4}$ & -0.01 \\
$\mathrm{~N}^{\mathrm{o}}$ of partners & $\mathbf{0 . 1 1}$ & -0.04 & 0.04 \\
\hline
\end{tabular}

Table 4. Participant characteristics for controls by factor quartile.

\begin{tabular}{|c|c|c|c|c|}
\hline Variable & Category & Drinker & Red meat & Prudent \\
\hline \multirow[t]{4}{*}{ Age (years) } & 1 & 52.4 & 54.0 & 49.4 \\
\hline & 2 & 51.8 & 49.9 & 50.5 \\
\hline & 3 & 50.3 & 50.6 & 52.1 \\
\hline & 4 & 47.4 & 47.1 & 49.8 \\
\hline Education & 1 & 6.3 & 7.4 & 6.3 \\
\hline \multirow[t]{3}{*}{ (years) } & 2 & 7.0 & 7.1 & 6.2 \\
\hline & 3 & 6.7 & 6.6 & 7.3 \\
\hline & 4 & 7.7 & 6.5 & 7.9 \\
\hline Smoking & 1 & 3.9 & 4.8 & 5.6 \\
\hline \multirow[t]{3}{*}{ (cigarettes/day) } & 2 & 5.1 & 5.5 & 4.8 \\
\hline & 3 & 6.1 & 4.3 & 5.8 \\
\hline & 4 & 6.4 & 6.9 & 5.4 \\
\hline Meat & 1 & 7.8 & 2.5 & 7.7 \\
\hline \multirow[t]{3}{*}{ (servings/week) } & 2 & 5.3 & 4.2 & 6.1 \\
\hline & 3 & 5.1 & 6.4 & 5.1 \\
\hline & 4 & 3.8 & 8.9 & 3.0 \\
\hline Vegetables & 1 & 3.9 & 2.8 & 1.3 \\
\hline \multirow[t]{3}{*}{ (servings/week) } & 2 & 3.4 & 3.2 & 2.5 \\
\hline & 3 & 2.9 & 3.4 & 3.6 \\
\hline & 4 & 2.0 & 2.8 & 4.9 \\
\hline \multirow[t]{4}{*}{ Age of first intercourse } & 1 & 19.5 & 19.5 & 20.3 \\
\hline & 2 & 20.0 & 19.1 & 19.5 \\
\hline & 3 & 18.9 & 20.4 & 18.8 \\
\hline & 4 & 19.2 & 19.7 & 19.1 \\
\hline \multirow[t]{4}{*}{$\mathrm{N}^{0}$ partners } & 1 & 1.7 & 1.9 & 1.6 \\
\hline & 2 & 1.8 & 2.3 & 2.1 \\
\hline & 3 & 1.8 & 2.6 & 1.8 \\
\hline & 4 & 2.1 & 2.9 & 1.8 \\
\hline
\end{tabular}

\footnotetext{
${ }^{1}$ Numbers in each cell corresponds to mean values of the variable.
}

Odds ratios of cervical cancer for dietary patterns are shown in Table 5. Cancer of the cervix was positively associated with red meat and drinker patterns (OR for highest category versus the lowest one for red meat pat- tern $1.79,95 \%$ CI 1.12-2.86, p-value for linear trend $=$ $0.02)$. On the other hand, cervical cancer was inversely associated with the prudent pattern (OR 0.60, 95\% CI 0.38-0.93). 
Table 5. Odds ratios of carcinoma of the cervix for dietary patterns ${ }^{1}$.

\begin{tabular}{|c|c|c|c|c|}
\hline Dietary pattern & Category & Cases/Controls & OR & $95 \%$ CI \\
\hline \multirow[t]{6}{*}{ Drinker } & Low & $60 / 134$ & 1.0 & reference \\
\hline & 2 & $54 / 134$ & 1.07 & $0.66-1.71$ \\
\hline & 3 & $68 / 134$ & 1.23 & $0.78-1.94$ \\
\hline & High & $86 / 134$ & 1.49 & $0.95-2.31$ \\
\hline & & $\mathrm{p}$-value for trend & \multicolumn{2}{|c|}{0.053} \\
\hline & & Continuous & 1.08 & $0.99-1.18$ \\
\hline \multirow[t]{6}{*}{ Red meat } & Low & $47 / 134$ & 1.0 & reference \\
\hline & 2 & $65 / 134$ & 1.31 & $0.81-2.12$ \\
\hline & 3 & $61 / 134$ & 1.30 & $0.81-2.10$ \\
\hline & High & $95 / 134$ & 1.79 & $1.12-2.86$ \\
\hline & & $\mathrm{p}$-value for trend & \multicolumn{2}{|c|}{0.02} \\
\hline & & Continuous & 1.13 & $1.00-1.28$ \\
\hline \multirow[t]{6}{*}{ Prudent } & Low & $87 / 134$ & 1.0 & reference \\
\hline & 2 & $71 / 134$ & 0.87 & $0.57-1.33$ \\
\hline & 3 & $57 / 134$ & 0.67 & $0.43-1.04$ \\
\hline & High & $53 / 134$ & 0.60 & $0.38-0.93$ \\
\hline & & $\mathrm{p}$-value for trend & \multicolumn{2}{|c|}{0.01} \\
\hline & & Continuous & 0.83 & $0.73-0.95$ \\
\hline
\end{tabular}

${ }^{1}$ Adjusted for age, residence, education, income, age at first intercourse, number of partners, smoking, total energy intake and all scores for dietary patterns.

\section{DISCUSSION}

To our knowledge, the present study is the first one on factor analysis and risk of cervical cancer. The principal components approach has some limitations related to the FFQ and the management of the data. The inclusion of foods and beverages should be validated previously to the factor analysis being run. In fact, principal components analysis should be conducted in order to obtain the simple structure following Thurstone's criteria $[15,16]$. In our model, this simple structure was obtained through the rotated principal components analysis.

In our study, an early age at first intercourse, a high number of sexual partners, and a high number of livebirths were directly associated with cervical cancer risk, replicating previous reports [3,17-19]. It has been suggested that the male factor could be related to the etiology of cervical cancer through venereal diseases, which could foster the infection of their spouses with HPV [17-21]. The drinker pattern displayed a clear gradient associated with the number of partners, and so did the red meat pattern.

In the present study, cigarette smoking did not signify an important risk in cancer of the cervix. It should be noted that in general, the intensity of smoking and the duration of this habit are not particularly high among women of low socioeconomic status in Uruguay [22]. Furthermore, when cigarette smoking was controlled by the above sexual and reproductive variables, the risk was close to null. Nevertheless, smoking intensity displayed a positive gradient for the drinker pattern. It is worth noting that Gunnell et al. [23] also found a synergy between HPV infection and smoking duration.

The role of red meat was positively associated with cervical cancer in our study. This could be explained by the presence of heterocyclic amines in red meat, which are powerful carcinogens in animals [24]. Moreover, red meat is an important source of fat and cholesterol and it has been suggested that whereas heterocyclic amines act as initiators, fat plays a role of promoter [25]. Further studies on the role of red meat in cervical cancer are warranted.

Finally the effect of total vegetables and total fruits was particularly protective in the etiology of cervical cancer [26]. This applies mainly to the strata of women with a high number of sexual partners. In fact, vegetables and fruits were the main components of the prudent pattern.

Like other case-control studies, this study has its limitations and strengths. The major limitations are selections bias, recall bias, and the possibility of error due to multiple comparisons (that is, chance findings). Perhaps, the lack of information about HPV status is a major limitation. Therefore, in the place of HPV we attempted to use the age at first intercourse and number of partners as proxy indicators of this infection. Another limitation is the rather small amount of foods used as a routine in the 
FFQ administered by the Cancer Institute. Among the strengths, in the first place, is the power of the study, measured by the sampling adequacy, which allowed the estimation of small ORs as significant. Secondly, all the cases were validated by expert pathologists, and finally, the high response rate among cases and controls suggests that participants were drawn from the same population base.

In summary, we conducted a factor analysis on the relationship between foods and beverages and risk of cervical cancer. Whereas the red meat pattern was directly associated with this malignancy, the prudent pattern was inversely associated with cancer of the cervix. In short, the main novelty of this study is the use of factor analysis in cervical cancer to evaluate the role of diet in this malignancy.

\section{REFERENCES}

[1] Barrios, E., Vassallo, J.A., Alonso, R., Garau, M. and Musetti, C. (2010) III Atlas de Incidencia del Cáncer en el Uruguay. Registro Nacional de Cáncer. Comisión Honoraria de Lucha contra el Cáncer, 87-88 (In Spanish).

[2] De Stefani, E., Fierro, L., Barrios, E. and Ronco, A. (1994) Cancer mortality trends in Uruguay 1953-1991. International Journal of Cancer, 56, 634-639. doi:10.1002/ijc.2910560505

[3] Schiffman, M.H., Brinton, L.A., Devesa, S.S. and Fraumeni, J.F. (1996) Cervical cancer. In: Schottenfeld, D. and Fraumeni, J.F. Eds. Cancer Epidemiology and Prevention. Second Edition. Oxford University Press, New York, 1090-1116.

[4] IARC Monographs on the evaluation of carcinogenic risks to humans. (2004) Tobacco smoke and involuntary smoking, 83, Lyon, France, 743-792.

[5] World Cancer Research Fund/American Institute for Cancer Research (2007) Food, nutrition, physical activity, and the prevention of cancer: A global perspective. AICR, Washington DC, 302-304.

[6] Mulaik, S.A. (2010) Foundations of Factor Analysis. Second Edition, CRC Press, Boca Raton, 276-279.

[7] De Stefani, E., Deneo-Pellegrini, H., Boffetta, P., et al. (2009) Dietary patterns and risk of cancer: A factor analysis in Uruguay. International Journal of Cancer, 124, 1391-1397. doi:10.1002/ijc.24035

[8] Ronco, A.L., De Stefani, E., Boffetta, P., et al. (2006) Food patterns and risk of breast cancer: A factor analysis study in Uruguay. International Journal of Cancer, 119, 1672-1678. doi:10.1002/ijc.22021

[9] Dixon, L.B., Balder, H.B., Virtannen, M.J., et al. (2004) Dietary patterns associated with colon and rectum cancer: Results from the Dietary Patterns and Cancer (DIETSCAN) Project. The American Journal of Clinical Nutrition, 80, 1003-1011.

[10] Slattery, M.L., Boucher, K.M., Cann, B.J., et al. (1998)
Eating patterns and risk of colon cancer. American Journal of Epidemiology, 148, 4-16.

[11] Gorsuch, R.L. (2008) Factor Analysis. Second Edition. Psychology Press, Taylor \& Francis Group, London, 234236.

[12] Thomson, G.H. (1951) The factorial analysis of human ability. University of London Press, London.

[13] Rothman, K.J., Greenland, S. and Lash, T. (2008) Modern epidemiology. Third Edition. Lippincott Williams \& Wilkins, Philadelphia, 303-327.

[14] StataCorp. (2007) Stata Statistical Software. Release 10. College Station, StataCorp LP, Texas.

[15] Thurstone, L.L. (1947) Multiple factor analysis: A development and expansion of vectors of the mind. University of Chicago Press, Chicago.

[16] Kline, P. (2002) An easy guide to factor analysis. Routlege, New York.

[17] Brinton, L.A., Reeves, W.C., Brenes, M.M., et al. (1989) The male factor in the etiology of cervical cancer among sexually monogamous women. International Journal of Cancer, 44, 199-203. doi:10.1002/ijc.2910440202

[18] Muñoz, N., Bosch, F.X., Shah, K.V., Meheus, A. (Editors) (1992) The epidemiology of human papillomavirus and cervical cancer. IARC Scientific Publications, Lyon.

[19] Bosch, F.X., Manos, M.M., Muñoz, N., et al. (1995) Prevalence of human papillomavirus in cervical cancer: A worldwide perspective. Journal of the National Cancer Institute, 87, 796-802. doi:10.1093/jnci/87.11.796

[20] Herrero, R., Potischman, N., Brinton, L.A., et al. (1991) A case-control study of nutrient status and invasive cervical cancer: I. dietary indicators. American Journal of Epidemiology, 134, 1335-1346.

[21] Castellsagué, X., Bosch, F.X., Muñoz, N., et al. (2002) Male circumsion, penile human papillomavirus infection, and cervical cancer in female partners. The New England Journal of Medicine, 346, 1105-1112. doi:10.1056/NEJMoa011688

[22] Carámbula, J.A., Ronco, A.L. and Niedworok, N.T. (1995) Investigación sociolaboral del tabaquismo en el Uruguay urbano. Programa Nacional de Prevencion del Cáncer de Pulmón. Dirección General de Salud. Ministerio de Salud Pública, Academia Nacional de Medicina, Uruguay, (In Spanish).

[23] Gunnell, A.S., Tran, T.N., Torrang, A., et al. (2006) Synergy between cigarette smoking and human papillomavirus type 16 in cervical cancer in situ development. Cancer Epidemiology, Biomarkers \& Prevention, 15, 21412147. doi:10.1158/1055-9965.EPI-06-0399

[24] Sinha, R. (2002) An epidemiologic approach to studying heterocyclic amines. Mutation Research, 506-507, 197204. doi:10.1016/S0027-5107(02)00166-5

[25] Weisburger, J.H. (2002) Comments on the history and importance of aromatic and heterocyclic amines in public health. Mutation Research, 506-507, 9-20. doi:10.1016/S0027-5107(02)00147-1

[26] IARC Handbooks of Cancer Prevention. (2003) Fruit and Vegetables. IARC Press, Lyon, 8, 89-92. 